\title{
Immobilization of Selected Microbes at Some Selected Solid Supports for Enhanced Fermentation Process
}

Rukshika Shalani Hewawasam ${ }^{1}$, Chandani Udawatte ${ }^{2}$, Sisira Kumara Weliwegamage ${ }^{2 *}$, Subramanium Sotheeswaran ${ }^{2}$ and Sanath Rajapakse ${ }^{2}$

${ }^{1}$ Post Graduate Institute of Science, University of Peradenisya, Peradeniya, Sri Lanka

${ }^{2}$ College of Chemical Sciences, Institute of Chemistry Ceylon, Rajagiriya, Sri Lanka

${ }^{3}$ Department of Molecular Biology and Biotechnology, Faculty of Science, University of Peradeniya, Sri Lanka

\begin{abstract}
Immobilization of macro molecules (such as enzymes) and micro-organisms can be generally defined as a procedure leading to their restricted mobility. Advantages of immobilization include easy separation of the enzymes/cells from the product and reuse of the enzymes/cells. In this research coconut tree leaf sheath was used to immobilize selected microbes which were used in fermentation tecnology. Coconut tree leaf sheath contains cellulose fiber layers which have cross linking between them. Sacchromyces cerevisiae was used as the microbial type due to widespread use in fermentation process. Microbes were entrapped within cellulose layers. Coconut tree leaf sheath was found to be an effecient solid support for immobilization. Immobilized microbes can be reused for fresh fermentation media. Immobilization can be carried out utilizing naturally avavilable coconut tree leaf sheath as a solid support, it's usage is very cost-effective and eco-froiendly method rather than using synthetic or semi synthetic solid supports.
\end{abstract}

Keywords: Immobilization; Coconut tree leaf sheath; Sacchromyces cerevisiae

\section{Introduction}

Immobilization technique is a versatile and economical method that is used in industries [1]. Advantages of immobilization include easy separation of the enzymes/cells from the product and reuse of the enzymes/cells. Further the favorable environment at support allows better colonizing and population increase in micro-organisms which in turn leads in better fermentation. The micro environment in the solid adsorbent protects the microorganisms from unfavorable conditions such as high alcohol concentration; low $\mathrm{pH}$ etc. Reuse of enzymes/cells makes the process economically more feasible with higher substrate conversion efficiencies. Immobilization can be carried out in several approaches such as physical adsorption, chemisorptions, entrapment, and cross linkages [2]. In this study, physical adsorption was considered. Physical adsorption can be accomplished in two ways: non- specific adsorption and specific adsorption. Between them, non-specific adsorption is the simplest and easiest way of immobilization. Hence it is economically effective. Generally immobilization is carried out using synthetic resins or semi synthetic resins [3]. Use of novel supports such as mesoporous silicas, hydrogels, and smart polymers, and cross-linked enzyme aggregates (CLEAs) is in trend nowadays [4]. Synthetic resins and semi synthetic resins have several disadvantages over natural solid supports. Some are polymer compounds can be leached out to products and polymer support can be toxic to enzymes due to change of $\mathrm{pH}$ or texture. Therefore activity of enzymes can be degraded [5].

In this research naturally available substances were tested for immobilization of microbe which helps in beverage fermentation.

Coconut tree leaf sheath (Figure 1) is consisting of cellulose layers all over it. Hence it's having high tensile strength as well as high surface area [6]. Large numbers of pores are included among cellulose layers. In these pores, cells of microorganism can be entrapped or can form non-specific bonds such as vander-waal bonds and hydrogen bonds with cellulose layers. On the other hand coconut leaf sheath is an ecofriendly, cost effective substance. It is inert which do not show any adverse or toxic effect on micro-organisms. Approximate availability of

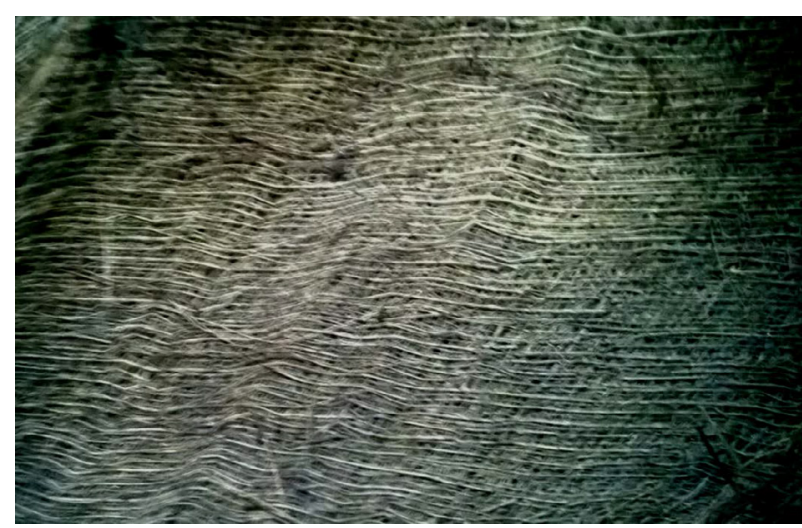

Figure 1: Coconut tree leaf sheath.

coconut tree leaf sheath is 9000 tons per year in worldwide [7]. So it is sufficiently available in world wide. Therefore usage of coconut tree leaf sheath is more feasible.

Coconut tree leaf sheath consist of cellulose layers (Figure 2) [8]. Due to -OH functional groups of cellulose, it can be induced inter and intra hydrogen bonding in between cellulose layers.

Saccharomyces cerevisiae is traditionally used in many fermentation

*Corresponding author: Weliwegamage SK, College of Chemical Sciences, Institute of Chemistry Ceylon, Rajagiriya, Sri Lanka, Tel: +94112053148, E-mail: weliwegama@yahoo.com

Received August 25, 2014; Accepted July 15, 2015; Published July 22 , 2015

Citation: Hewawasam RS, Udawatte C, Weliwegamage SK, Sotheeswaran S, Rajapakse S (2015) Immobilization of Selected Microbes at Some Selected Solid Supports for Enhanced Fermentation Process. Ferment Technol 4: 115 doi:10.4172/2167-7972.1000115

Copyright: (c) 2015 Hewawasam RS, et al. This is an open-access article distributed under the terms of the Creative Commons Attribution License, which permits unrestricted use, distribution, and reproduction in any medium, provided the original author and source are credited. 


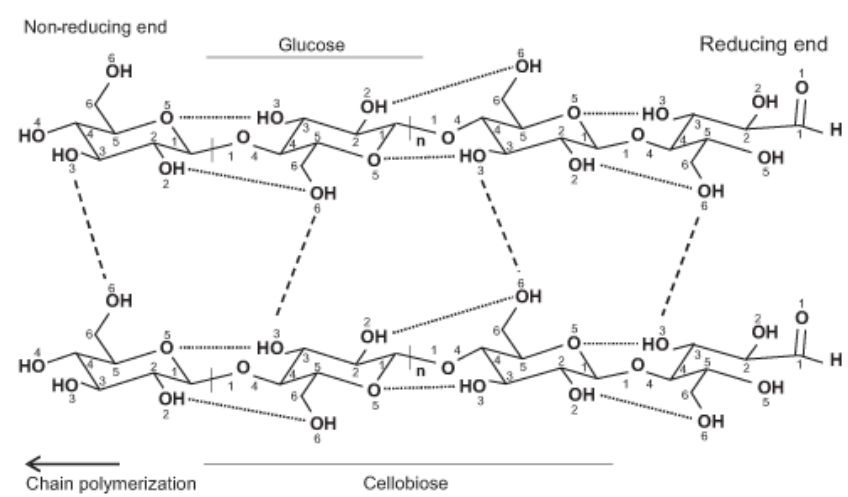

Figure 2: The structure and the inter and intra chain hydrogen bonding pattern in cellulose layers. Dashed line-inter chain hydrogen bonding, Dotted lineintra chain hydrogen bonding [8]

processes. Generally Saccharomyces cerevisiae (Bakery Yeast) is used for fermentation in beverage industry. It uses simple sugars as a source of energy such as glucose and fructose or disaccharides such as sucrose and maltose. In anaerobic respiration process, alcohols and some organic acids are generated from sugar substrates as byproducts in neutral or slightly acidic medium [9]. Therefore Sacchromyces cerevisiae is used in alcoholic beverage industry around the world.

Cell wall structure of Saccharomyces cerevisiae is important for immobilization. Saccharomyces cerevisiae cell wall represents $30 \%$ of the dry weight of the cell and is composed largely of polysaccharides (85\%) and proteins $(15 \%)[10,11]$. From that percentage of polysaccharides, glucan is present in $80-90 \%$ which is polymerized by D-glucose monomer linking with glycosidic bonds [11]. The cell wall of Saccharomyces cerevisiae consists of two types of $\beta$-glucans. $\beta$ - $(1,3)$-glucan accounts for $50-55 \%$, whereas $\beta-(1,6)$-glucan represents $10-15 \%$ of the total Saccharomyces cerevisiae cell wall polysaccharides [11]. In addition to $\beta$-glucans, mannoproteins and $\mathrm{N}$-acetylglucosamine are also present in cell wall of Saccharomyces cerevisiae $\mathrm{N}$-acetylglucosamine can be linked through $\beta-(1-4)$ and mannoprotein residues can be linked to $\beta$ - $(1,6)$ glucan through a processed glycosylphosphatidylinositol or to $\beta-(1,3)$ glucan through alkali-labile bond [10,12-17]. Based on these analyses, a structure for Saccharomyces cerevisiae cell wall has been proposed [12,14,18-20] (Figure 3).

Cell wall mannoproteins (CWP) can be linked to the -1,3-glucan via alkali-sensitive bonds (ASB) or to PIR proteins (PIR) via a disulfide link (SS). GPI Cell Wall Proteins (GPI-CWP) are attached to the -1,6-glucan through a remnant GPI anchor (GPI Rem.). The links between -1,3-glucan and -1,6-glucan or PIR proteins are still uncharacterized [10].

Cell wall mannoproteins (CWP) can be linked to the -1,3-glucan via alkali-sensitive bonds (ASB) or to PIR proteins (PIR) via a disulfide link (SS). GPI cell wall proteins (GPI-CWP) are attached to the -1,6-glucan through a remnant GPI anchor (GPI Rem.). The links between -1,3-glucan and -1,6-glucan or PIR proteins are still uncharacterized [10].

A lower level of branching and polymerization degree is characterized by better solubility (Figure 4 ). It is believed that insoluble $\beta$-glucans are those whose degree of polymerization (DP) is higher than $100[21,22]$. Insoluble or slightly soluble $\beta$-glucans contain very long, multi-branched side chains in the particle (Figure 5).

\section{Instrumentation}

The double beam UV- Visible Spectrophotometer model HITACHI (U-2910) at Institute of Chemistry Ceylon was used for the UV- visible absorbance measurements.

The Gas Chromatograph (GC) model (GC4000/GL SCIENCES) at Institute of Chemistry Ceylon was used for obtaining ethanol concentration values.

The Scanning Electron Microscope model LEO (LEO 1420VP) at Industrial Technology Institute, Colombo, Sri Lanka was used for obtaining scanning electron microscopy images.

\section{Materials and Methodology}

As solid supports sterilized coconut tree leaf sheath and silica coated glass were used. Sacchromyces cerevisiae was used as microbial type.

Sacchromyces cerevisiae was incubated in $10 \mathrm{ml}$ of standard YPD

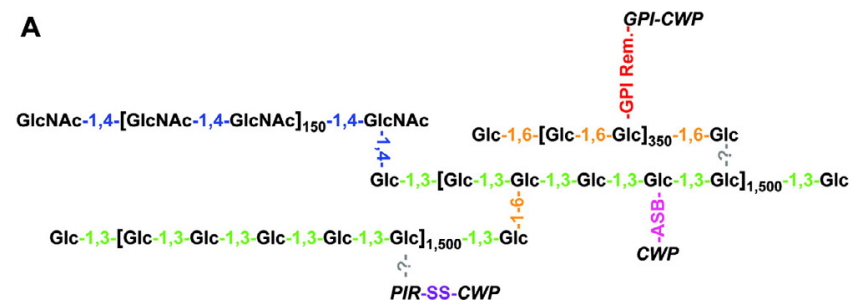

Figure 3: Schematic representation of cell wall components and their linkages The -1,3-, -1,4-,and -1,6-glucosidic bonds are represented as green, blue, and orange, respectively.

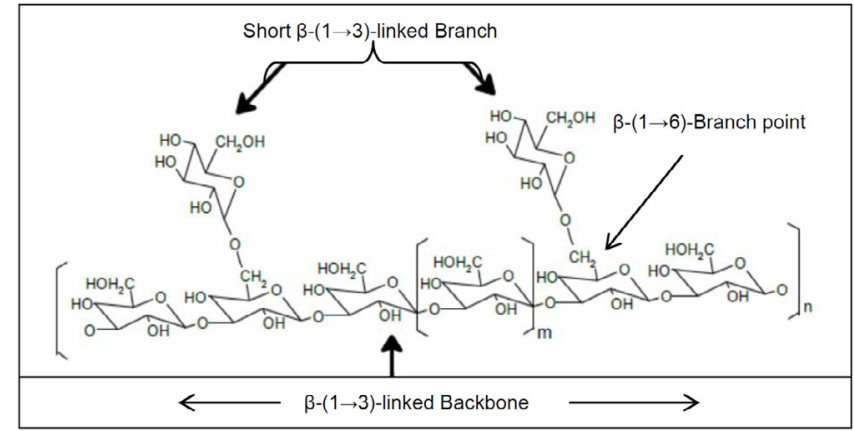

Figure 4: An example of the molecular structure of soluble yeast $\beta$-glucan [22]

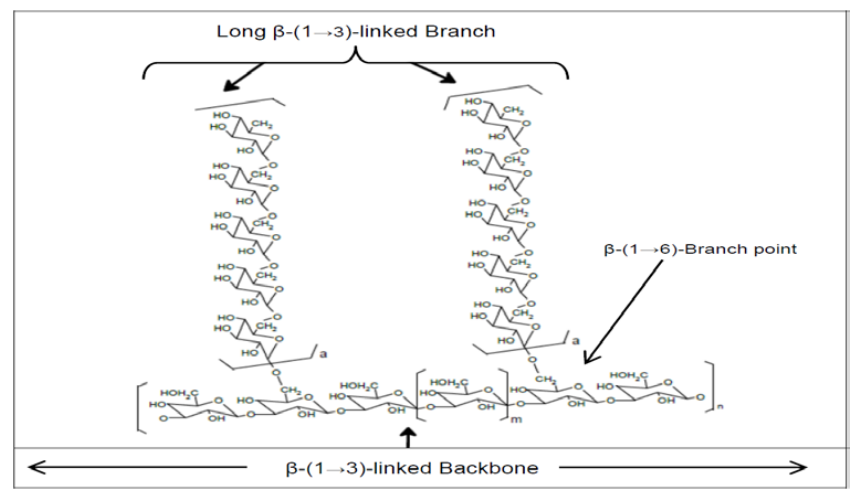

Figure 5: An example of the molecular structure of insoluble yeast $\beta$-glucan [22]. 
medium (Yeast/Dextrose/Peptone). When it reaches log phase in thier growth cycle [23] $1 \mathrm{ml}$ of medium was introduced to sterilized solid support. Solid support with immobilized microbe was washed with cool distilled water and dried for over night under aseptic techniques. Dried immobilzed microbes were introduced to $10 \mathrm{ml}$ of growth media. Sacchromyces cerevisiae was inoculated in to growth medium without solid support as the positive control. Absorbance was measured at 600 $\mathrm{nm}$ for 27 hours for the plotting of growth curve. Absorbance only of growth medium without inoculating Sacchromyces cerevisiae and in the absence of solid support was carried out as negative control.

As another method for ensuring the activity of immobilized microbes on the solid support; Ethanol production of microbes was measured. Dried immobilized microbe system was added to streilized sugar solution $(10 \mathrm{~g} / \mathrm{l})$. For a duration of 10 days ethanol concentration was monitored using gas chromotography. Column temperature was set at $80^{\circ} \mathrm{C}$ (Isothermal condition) and as the carrier gas $\mathrm{H} 2(30 \mathrm{ml} / \mathrm{min})$ was used. After 4 days, solid support was washed with sterilized water at room temperature $\left(28^{\circ} \mathrm{C}\right)$ and dried for over night under aseptic techniques. Using dynamic conditions, freshly prepared sugar solution $(10 \mathrm{~g} / \mathrm{l})$ was added to test reusability. Without solid support microbes were inoculated to standard sugar solution as negative controls.

To get the morphological features of immobilized Saccharomyces cerevisiae, dried coconut tree leaf sheath with immobilized microbe was subjected to Scanning Electron Microscope (SEM) imaging. SEM was operated at an accelerated voltage $18 \mathrm{kV}$ and at a working distance of a $15 \mathrm{~mm}$. The samples were gold plated by using gold sputter.

\section{Results and Discussion}

\section{Obtaining growth curves}

Immobilized Saccharomyces cerevisiae on coconut tree leaf sheath had lower gradient in log phase. Immobilized Saccharomyces cerevisiae had slower growth rate than Saccharomyces cerevisiae in culture. In comparison to yeast in culture [- $\bullet$, the population on solid support does not come to death phase after 25 hours. This suggests that coconut tree leaf sheath provides favorable environment for the microorganism for better growth (Figure 6). However with silica coated glass, no detectable growth was obtained. It was found that the coating also is unstable.

\section{Ethanol production by immobilized microbes}

Under static conditions the immobilized population shows a higher efficiency in ethanol production over control without solid support. The immobilized culture can be reused with similar efficiency (Figure 7).

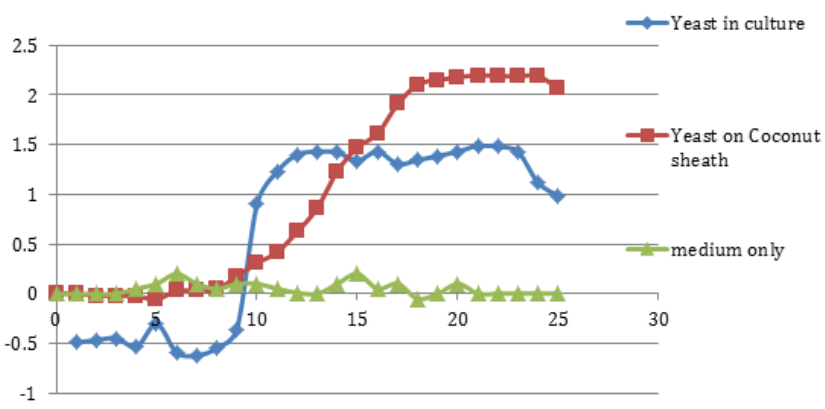

Figure 6: Growth curve of Saccharomyces cerevisiae with solid support (coconut tree leaf sheath), [- ] without solid support [ $\downarrow$ ] and without solid support and microorganism $[-\mathbb{-}-]$

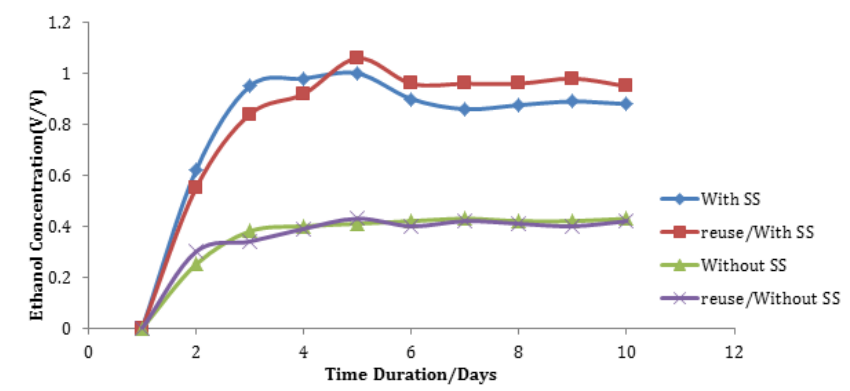

Figure 7: Ethanol production of Saccharomyces cerevisiae with solid support (SS) [--] (coconut tree leaf sheath) and without solid support $[-\mathbb{-}-]$ as a function of time (days).

\begin{tabular}{|l|c|c|c|}
\hline Day & $\begin{array}{c}\text { Ethanol concentration } \\
\text { of immobilized } \\
\text { Saccharomyces } \\
\text { cerevisiae (V/V) }\end{array}$ & $\begin{array}{c}\text { Ethanol concentration } \\
\text { of negative control } \\
\text { (V/V) }\end{array}$ & $\begin{array}{c}\text { Percentage of } \\
\text { increase in ethanol } \\
\text { production over } \\
\text { negative control }\end{array}$ \\
\hline 1 & 0 & 0 & 0 \\
\hline 2 & 0.62 & 0.25 & 59.6 \\
\hline 3 & 0.95 & 0.38 & 60.0 \\
\hline 4 & 0.98 & 0.40 & 59.1 \\
\hline 5 & 1.00 & 0.41 & 60.0 \\
\hline 6 & 0.90 & 0.42 & 53.3 \\
\hline 7 & 0.86 & 0.43 & 50.0 \\
\hline 8 & 0.87 & 0.42 & 51.7 \\
\hline 9 & 0.89 & 0.42 & 52.8 \\
\hline 10 & 0.88 & 0.43 & 51.1 \\
\hline
\end{tabular}

Table 1: Percentage increase of ethanol concentration of immobilized Saccharomyces cerevisiae on coconut tree leaf sheath over its negative control.

The immobilized culture produces higher percentage ethanol over unsupported culture under similar conditions which can be shown by the Table 1.

The percentage increase in ethanol yield was calculated by formula given below.

$\%$ Increase $=\frac{\text { Ethanol concentration by immobilized culture-Ethanol concentration by negative control }}{\text { Ethanol concentration by negative control }}$

Immobilized microbe was functionally active on coconut leaf sheath.

\section{SEM analysis}

According to Figure 8 it shows that coconut tree leaf sheath has large surface area with grooves in structure which can provide safe and favorable micro environments to the microorganism.

Saccharomyces cerevisiae was adsorbed physically and none specifically in to coconut leaf sheath according to Figure 9. This figure shows the efficient colonizing at the solid support. The nutrients which can be absorbed from coconut leaf sheath to microorganism may be an additional advantage towards efficient colonizing.

Coconut tree leaf sheath consist of mostly with cellulose layers (Figure 8). Due to $-\mathrm{OH}$ functional groups of cellulose, it can be induced inter and intra hydrogen bonding in between cellulose layers. This hydrogen bonding can be produced with $-\mathrm{OH}$ groups of cell wall of Saccharomyces cerevisiae. Saccharomyces cerevisiae can be attached through vanderwalls interaction and hydrogen bonding to coconut tree leaf sheath. 
Citation: Hewawasam RS, Udawatte C, Weliwegamage SK, Sotheeswaran S, Rajapakse S (2015) Immobilization of Selected Microbes at Some Selected Solid Supports for Enhanced Fermentation Process. Ferment Technol 4: 115. doi:10.4172/2167-7972.1000115

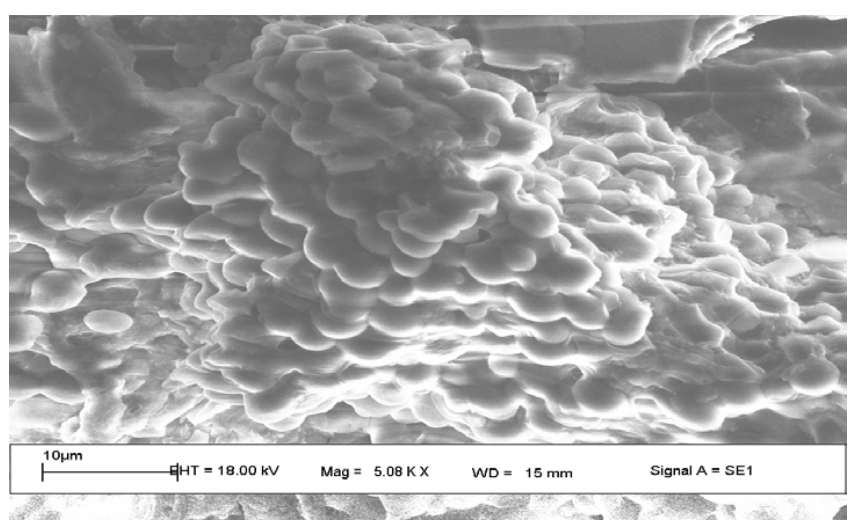

Figure 8: SEM analysis for coconut tree leaf sheath under 101 magnification.

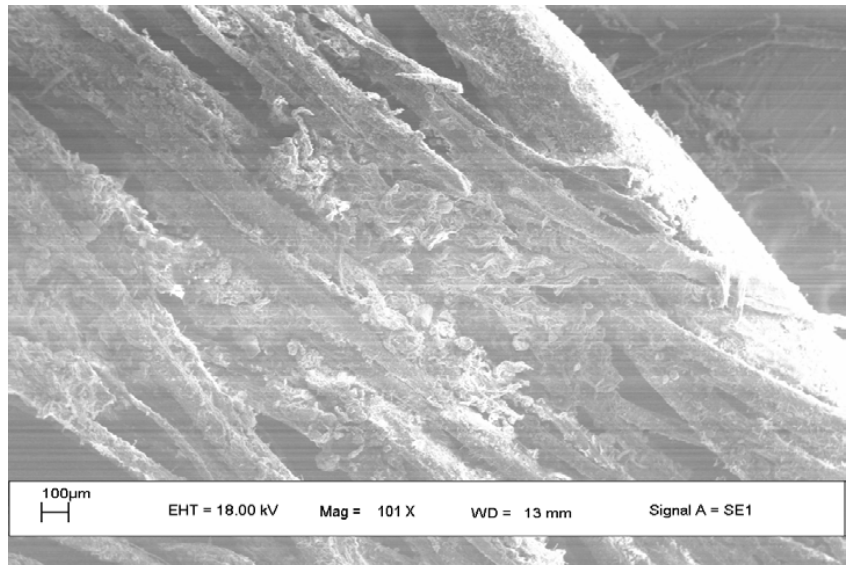

Figure 9: SEM analysis for immobilized Saccharomyces cerevisiae on coconut leaf sheath under $5.08 \times 10^{3}$ magnification.

Coconut tree leaf sheath is an effecient solid support for immobilization. Immobilized microbes can be reused in fresh fermentation media.If immobilization can be carried out utilizing naturally avavilable substances as solid supports, it will be very costeffective and eco-froiendly.

\section{Acknowledgement}

Authors wish to thank the National Science Foundation of Sri Lanka NSF/ $\mathrm{SCH} / 13 / 05$ for research funds, the Institute of Chemistry Ceylon, Department of Molecular Biology and Biotechnology, Faculty of Science, University of Peradeniya and Industrial Technology Institute for providing research facilities.

\section{References}

1. Groboillot A, Boadi DK, Poncelet D, Neufeld RJ (1994) Immobilization of cells for application in the food industry. Crit Rev Biotechnol 14: 75-107.

2. Stryer $L$ (1995) Biochemistry. Freeman, New York.

3. Spahn C, Minteer SD (2008) Enzyme Immobilization in Biotechnology. Recent Patents on Engineering 2: 195-200.

4. Sheldon RA, van Pelt S (2013) Enzyme immobilisation in biocatalysis: why, what and how. Chem Soc Rev 42: 6223-6235.

5. S.A.Costa, Helena S. Azevedo, and Rui L Reis (2004) Enzyme Immobilization in Biodegradable Polymers for Biomedical Applications. 17: 301.

6. Sapuan SM, Zan MNM, Zainudin ES, Arora P R (2005) Tensile and flexural strengths of coconut spathe-fibre reinforced epoxy composites. Journal of Tropical Agriculture 43 (1-2): 63-65.
7. Satyanarayana KG, Pillai C K, Sakumaran K, Rohatgi PK, Vijayan K (1982) Structure property studies of fibers from various parts of the coconut tree. Journal of Materials Science 17: (2453-2462).

8. Reginaldo A, Festucci-Buselli, Wagner C Otoni, Chandrashekhar P Josh (2007) Structure, organization, and functions of cellulose synthase complexes in higher plants. Brazilian Journal of Plant Physiology 19: 1.

9. Dorta C, Oliva-Neto P, De-Abreu-Neto MS, Nicolau-Junior N, Nagashima Al (2005) Synergism among lactic acid, sulfite, $\mathrm{pH}$ and ethanol in alcoholic fermentation of Saccharomyces cerevisiae (PE-2 and M-26). World Journal of Microbiology \& Biotechnology 22: 177-182.

10. Nguyen TH, Fleet GH, Rogers PL (1998) Composition of the cell walls of several yeast species. Appl Microbiol Biotechnol 50: 206-212.

11. Lesage G, Bussey H (2006) Cell wall assembly in Saccharomyces cerevisiae. Microbiol Mol Biol Rev 70: 317-343.

12. Aimanianda V, Clavaud C, Simenel C, Fontaine T, Delepierre M, et al (2009) Cell wall beta-(1,6)-glucan of Saccharomyces cerevisiae: structura characterization and in situ synthesis. J Biol Chem 284: 13401-13412.

13. Dijkgraaf GJ, Li H and H Bussey (2002) Cell wall ß-glucans of Saccharomyces cerevisia . In: Steinbuchel A (ed.) Biopolymers. Wiley-VCH, Weinheim, pp. 179210 .

14. Kapteyn JC, Van Den Ende H, Klis FM (1999) The contribution of cell wall proteins to the organization of the yeast cell wall. Biochim Biophys Acta 1426 373-383.

15. Klis FM, Mol P, Hellingwerf K, Brul S (2002) Dynamics of cell wall structure in Saccharomyces cerevisiae. FEMS Microbiol Rev 26: 239-256.

16. Kollar R, Petrakova E, Ashwell G, Robbins PW and Cabib E (1995) Architecture of the yeast cell wall. The linkage between chitin and $\beta(1-3)$-glucan. J Bio Chem. 270: 1170-1178.

17. Kollár R, Reinhold BB, Petráková E, Yeh HJ, Ashwell G, et al. (1997)Architecture of the yeast cell wall. Beta(1-->6)-glucan interconnects mannoprotein, beta(1$>$ )3-glucan, and chitin. J Biol Chem 272: 17762-17775.

18. Mrsa V, Seidl T, Gentzsch M and Tanner W (1997) Specific labelling of cell wal proteins by biotinylation. Identification of four covalently linked O-mannosylated proteins of Saccharomyces cerevisiae. Yeast 13: 1145-1154.

19. Cabib E, Roh DH, Schmidt M, Crotti LB, Varma A (2001) The yeast cell wal and septum as paradigms of cell growth and morphogenesis. J Biol Chem 276 19679-19682.

20. Shahinian S, Bussey $H(2000)$ beta-1,6-Glucan synthesis in Saccharomyces cerevisiae. Mol Microbiol 35: 477-489.

21. Zekovic DB, Kwiatkowski S, Vrvic MM, Jakovljevic D, Moran CA (2005) Natural and modified (1-->3)-beta-D-glucans in health promotion and disease alleviation. Crit Rev Biotechnol 25: 205-230.

22. Bozena Waszkiewicz-Robak (2013) Lipid metabolism Spent Brewer's Yeas and Beta-Glucans Isolated from Them as Diet Components Modifying Blood Lipid Metabolism Disturbed by an Atherogenic Diet (chap 12).

23. Hewawasam RS, Jayawardhane MDCD, Udawatte C. Coconut water as a growth medium for Saccharomyces cerevisiae and Escherichia coli. Proceedings of the International Conference on Chemical Education 